\title{
Hypoglycemic and hypolipidemic potential of turmeric and black cumin in rat model
}

\author{
Sehar Mobeen ${ }^{1 *}$, Masood Sadiq Butt ${ }^{1}$, Mian Kamran Sharif ${ }^{1}$, Muhammad \\ Rizwan $^{2}$ and Sabahat Amin ${ }^{1}$ \\ 1. National Institute of Food Science and Technology, University of Agriculture, Faisalabad, Pakistan \\ 2. Department of Food Science and Technology, Faculty of Life Sciences, University of Central Punjab, Lahore, \\ Pakistan \\ *Corresponding author's email: seharuaf3708@gmail.com
}

Citation

Sehar Mobeen, Masood Sadiq Butt, Mian Kamran Sharif, Muhammad Rizwan and Sabahat Amin. Hypoglycemic and hypolipidemic potential of turmeric and black cumin in rat model. Pure and Applied Biology. Vol. 11, Issue 1, pp116128. http://dx.doi.org/10.19045/bspab.2022.110013

\begin{tabular}{llll}
\hline \hline Received: 03/12/2020 & Revised: 19/02/2021 & Accepted: 05/03/2021 & Online First: 21/05/2021 \\
\hline
\end{tabular}

\section{Abstract}

Diabetes Mellitus (DM) is a complex ailment that disturb metabolic process of body and prevalent worldwide. Natural products have gained substantial consideration in correcting diabetes and its associated level globally. This research is conducted to access the therapeutic potential of turmeric and black cumin to lessen the diet related malfunctioning like diabetes mellitus which is defined by elevated blood glucose level. Turmeric and black cumin both possess disease prevention properties like anti-diabetic, anti-hyperlipidemic, antioxidants and numerous others. Therapeutic effect of turmeric and black cumin was assessed by an efficacy study on streptozotocin induced diabetic rats. Rats were divided into 5 groups that are $\mathrm{G}_{0}$ consist of healthy rats, $\mathrm{G}_{1}$ consist of diabetic rats without giving any treatment, $\mathrm{G}_{2}$ involves diabetic rats received turmeric powder, $\mathrm{G}_{3}$ involves diabetic rats received black cumin powder and $\mathrm{G}_{4}$ consist of diabetic rats treated with combined mixture of turmeric powder and black powder. The objective of this study was to estimate the anti-diabetic role of turmeric and black cumin in rats. The result indicated that blood glucose level and serum lipid profile was greatly improved by combined mixture of turmeric and black cumin rather than the individual doses of turmeric and black cumin. Thus the result showed that turmeric and black cumin has potential to treat diabetes mellitus and related disorders.

Keywords: Black cumin; Blood glucose level; Diabetes mellitus; Serum lipid profile

\section{Introduction}

Natural products that are derived from plants and animal sources provide the basic ingredients for curing diseases. The importance of medicinal plants has been increasing day by day. These medicinal plants contain many active compounds that can be employed as therapeutic agent for correcting ailments. World health organization reported that $80 \%$ of the population is dependable on herbal plants because they provide better health outcomes. Many medicinal plants are considered as adjuvant therapy because they are not only beneficial for treatment of diseases but also used for the prevention of disease and maintenance of health [1].

Turmeric derived from the plant curcuma longa, is a spice and exhibit medicinal properties and widely used in the medical field as a remedy for diseases [2]. It is commonly known as haldi. Its rhizome are 
applaud, elongated having small branches. The active compound of turmeric is curcumin which is a polyphenol and gives yellow color to turmeric. Curcumin is very effective remedy for several diseases because it acts as anti-diabetic, anti-inflammatory, lipid lowering [3]. Curcumin is a polyphenol compound and it plays a vital part in treatment of ailments like reduces oxidative imbalance, treat diabetic complications, reduce high level of cholesterol and suppresses tumor [4].

Black cumin (Nigella sativa) is commonly recognized as kalonji. In Arabic it is known by name Habbah el Baraka means the seed of blessing. The Nigella sativa originated from the saying of Prophet (PBUH) that "black cumin is the therapy for curing every sicknesses excluding death'. It is declared that Holy Prophet (PBUH), Himself utilized this seeds as a therapy for the treatment of ailments by adding it in honey. Ibni Sina also concern about this seed that "it boost up the body's vigor and provide relieve from lethargy"' [5]. Furthermore, Nigella sativa seeds consist of different alkaloids namely isoquinoline and pyrazole alkaloids. For example are nigellimine, nigellidine and nigellicine. Nigella sativa seeds are also rich source of unsaturated fatty acids that are palmitic, linoleic and oleic acid. These fatty acids are beneficial for health and helps in lowering cholesterol level [6].

Nigella sativa contain abundance of phytochemicals and also rich in antioxidants and other nutritional rich compounds that should be utilized on regular basis. It has been regarded as 'seed of blessing' because it has strong therapeutic potential to prevent against 2 major disease such as cardiovascular disease and cancer that are leading cause of death in U.S. Black cumin is proving very successful in disease control and it fights with the actual reason of symptoms of the disease. Black cumin modulates the weaker immune system.
Thymoquinone which is active component of black cumin has powerful anti-inflammatory potential and beneficial in cleaning the toxin of body [7].

Diabetes mellitus is an epidemic worldwide metabolic disease that causes hyperglycemia with defects in the production of insulin and it leads to changes in the metabolism of nutrients like carbohydrates, proteins and fats. Most common indications of diabetes are increased appetite, increased urination and greater thirst. There are 2 type of diabetes mellitus which are type I and type II recognized as insulin dependent and noninsulin dependent diabetes mellitus. Type 1 diabetes mellitus is a state in which beta cells that manufacture insulin are demolished. It is diagnosed before 30 years of age. Type 2 diabetes mellitus is a state when pancreas unable to make sufficient insulin and results in lack of insulin production. It is diagnosed after the 40 years of age [8].

Diabetes mellitus is a serious metabolic syndrome and its resultant mortality and morbidity is tremendously increasing day by day. Some risk factors that contribute to DM include smoking, alcohol, obesity, diet, overweight, vascular or cardiovascular disease, physical activity levels, hormones and certain medical treatments. Exercise and diet will help improve lifestyle habits and reduce the risk of developing diabetes. Plants and plant derived product are effective in curing diabetes and related disorders. Almost half of the patients with diabetes mellitus are suffering from the consequences of heart disease such as coronary artery disease. In this condition plaque in the arteries developed. The patient with type 2 diabetes mellitus has more chances of getting heart illness than non-diabetic person. In diabetes mellitus, abnormal lipid profile, rise in Low density lipoprotein (LDL) and decrease in High density lipoprotein (HDL) give rise to condition known as dyslipidemia. Diabetes mellitus itself does not raise the level of Low 
density lipoprotein (LDL) but small tightly packed particles LDL particles present in diabetes mellitus causing abnormality in the cholesterol level and are more prone to oxidation. Because of increased threats of high blood pressure and diabetic dyslipidemia, the chances of heart problems such as stroke and other heart complications raised in diabetic people [9].

Oxidative stress happens when balance of antioxidants disrupt due to different conditions like inflammation, aging and drug addiction. Oxidative stress attacks the body cells and disturbs their functions. Oxidative stress is crucial in diabetes mellitus as it plays a key role in progression of diabetes mellitus. Reactive oxygen species produce killing response and its level raise in the diabetes because of formation of enzymes like superoxide dismutase and catalase antioxidants. Changes in level of such enzymes create the tissue vulnerable to oxidative imbalance that will ultimately cause diabetes related problems $[10,11]$.

Turmeric is used for the treatment of diabetes mellitus type 1 and type 2. Turmeric utilization helps in the up regulation of genes that are involve in the breakdown of glucose and also turmeric down-regulate the genes with insulin synthesizing impact [12]. Turmeric possesses hypoglycemic potential as it protects pancreatic $\beta$-cells from impairment, which is because of imbalance of free radicals and impose specific impact on glucose implementation and production of insulin. Turmeric is beneficial in the improvement of insulin sensitivity by binding to peroxisome proliferator activating receptor gamma (regulate glucose metabolism) [13].

Turmeric possesses three effects that are; enhancement in the production of insulin, upgrade action of enzymatic activities like catalase, superoxide dismutase, glutathione peroxidase and diminished lipid peroxidation that helps to prevent cardiovascular risk factors in diabetic patient $[14,15]$. Curcumin which is principle compound of turmeric contain curcuminoids that have several disease prevention properties such as antioxidant, anti-diabetic, hepatoprotective and also beneficial for the health of heart [16].

Curcumin is also helpful for the regulation of lipid uptake that involves in progression of obesity and related difficulties. Curcuminoids are yellow color a pigment belongs to the compound diarlyheptanoids. These polyphenol compounds are present in the turmeric in the composition of $3-15 \%$ and curcumin being the main compound in them. Curcumin is basically known as diferuloyl methane is a yellow powder with the molecular weight 368.37 [17]. Curcumin is composed of several curcuminoids which are curcumin I which contributes almost $17 \%$ curcumin, curcumin II which is known as dimethoxycurcumin constitute $17 \%$, curcumin III known as bisdimethoxycurcumin approximately $3 \%$ curcumin and curcumin IV named cyclocurcumin are also present [18]. Curcuminoids demonstrate similar biological action like that of curcumin. These curcuminoids are produced from the extract that is obtained from turmeric. The curcuminoids caused lessening of blood sugar level through the activation of peroxisome proliferate activated receptor and adipocyte differentiation in diabetic mice model. In addition to anti-diabetic effect, curcuminoids are also beneficial in the normalization lipid profile by the degradation of lipids [19].

Black cumin (Nigella sativa) contains many active components in it that impose favorable impact in treating different diseases. The active compounds present in Nigella sativa seed are thymoquinone, dithymoquinone (DIM), 4-terpineol, carvacrol, carvone, tanethol, $\alpha$-pinene, thymol, $\alpha$-hederin, limonene and numerous other constituents present in little amount. Thymoquinone is the 
most active compound of Nigella sativa seed plant and most of disease prevention properties of this plant are attributed to thymoquinone [20]. Black cumin and its compounds are effective in the improvement of blood glucose level. Oxidative stress is important factor in generating diabetes mellitus because oxidative stress reduces effectiveness of $\beta$-cell of pancreas that causes issues in the production of insulin. Nigella sativa and its compounds are proved beneficial in reducing the oxidative imbalance and protect the pancreatic $\beta$-cells from mutilation. Nigella sativa also exert protective effect in correcting lipid abnormalities and exhibit antihypercholesterimia potential. Nigella sativa and components prevent hypercholesterimia by reduction of HMG-CO reductase enzyme and protect LDL oxidation and provide protection from free radical and act as antihyperlipidemia plant [21].

\section{Materials and Methods}

Preparation of powder Turmeric and black cumin were obtained from the local market of Faisalabad. Then the turmeric and black cumin were crushed to make a fine powder. After all, this powder was mixed in the diet of rats. This research was carried out in the National Institute of Food Science and Technology, University of Agriculture, Faisalabad.

\section{Efficacy trial}

\section{Experimental design}

The bio-efficacy trial carried out on rats to test the therapeutic potential of turmeric and black cumin in controlling hyperglycemia. The study was carried out for a period of 45 days on rats. Adult albino rats weighing between 185-200 g were collected from the animal house, from National Institute of Food Science and Technology, University of Agriculture Faisalabad. They were retained carefully in clean cages. They were fed by normal diet. Rats undergo natural period in which they were exposed to light of $12 \mathrm{~h}$ throughout the experiment. All rats were receiving diet that meets their basic need 2 weeks before experiment for growth maintenance and their adaptation. They were kept maintained in their appropriate groups for 6 weeks and assessed on daily basis.

\section{Efficacy study plan}

20 albino rats weighing 185-200 g were obtained and reserved in the animal house of National Institute of Food Science and Technology.

Efficacy study was consisted of 5 groups

$\mathrm{G}_{0}$ : Control rats (Non-diabetic and did not given any treatment)

$\mathrm{G}_{1}$; Diabetic rats (did not receive any treatment)

$\mathrm{G}_{2}$ : Diabetic rats (received turmeric powder $2 \mathrm{~g}+$ normal diet for 6 weeks)

$\mathrm{G}_{3}$ : Diabetic rats (received black cumin powder $3 g$ + normal diet for 6 weeks)

$\mathrm{G}_{4}$ : Diabetic rats (received combination of turmeric powder $1 \mathrm{~g}$ and black cumin powder $1.5 \mathrm{~g}$ for 6 weeks).

\section{Induction of diabetes}

The experimental animals were fasted for 12 $\mathrm{h}$ and then diabetes was induced by injecting Streptozotocin $50 \mathrm{mg} / \mathrm{kg}$ solution prepared by mixing in $0.1 \mathrm{M}$ citrate buffer to rats. After injection, all animals were returned to their cages and given free access to food and water. After 3 days blood glucose was determined using glucometer and animals that showed blood glucose level above $250 \mathrm{mg} / \mathrm{dl}$ were considered diabetic and selected for the study.

\section{Blood glucose level}

Blood sample was collected from the rats before giving treatment with turmeric and black cumin and every 15 day after the treatment has been given to them. Blood sample was collected with sharp razor and blood glucose level was determined by glucometer [22].

\section{Serum lipid profile}


Serum lipid profile includes total cholesterol, high density lipoproteins, low density lipoproteins and triglycerides was measured [23].

\section{Statistical analysis}

The obtained data was undergone statistical analysis by the method given by Montgomery [24].

\section{Results}

Herbs and spices are employed for medicinal purposes for centuries. They have potential to lessen the risk of non-communicable maladies because of their role as source of nutritive polyphenols. Polyphenols are generally exist in the various plant derived substance comprising herbs and spices and they possess antioxidant properties due to which they are beneficial in maintaining health and provides protection against numerous diseases. Turmeric and black cumin are added in the food as spice or preservative and they are effective remedy for curing numerous diseases. Present study divided into 5 groups that are $\mathrm{G}_{0}$ normal rats, $\mathrm{G}_{1}$ diabetic rat, $\mathrm{G}_{2}$ diabetic receiving turmeric powder, $\mathrm{G}_{3}$ diabetic receiving black cumin powder and $\mathrm{G}_{4}$ combination of turmeric and black cumin powder. The purpose of present research was to assess the hypoglycemic potential of turmeric and black cumin in rat model. First of all powdered turmeric and black cumin was analyzed for nutritional composition and then they were given to rats for the evaluation of blood glucose and other parameters. At the end data was exposed to statistical analysis to check the significance of result.

\section{Blood glucose}

During the period of 45 days blood sugar level of the rats was assessed 4 times that was at the start of study and then after every 15 days to check the anti-diabetic effect of turmeric and black cumin in rats. The results have shown that turmeric and black cumin and their mixture are beneficial in dropping blood glucose level. Mean Table 1 showed that blood glucose of non-diabetic normal rats was $108.75 \mathrm{mg} / \mathrm{dL}$ at 0 day and remained in normal range till the end of study. The blood glucose level was high in $\mathrm{G}_{1}, \mathrm{G}_{2}, \mathrm{G}_{3}$ and $\mathrm{G}_{4}$ by streptozotozin injection. In $\mathrm{G}_{1}$ blood glucose remained high during the whole study because this group received no treatment and in $\mathrm{G}_{2}, \mathrm{G}_{3}$ and $\mathrm{G}_{4}$ the value of blood glucose was decreased when these groups were treated with turmeric and black cumin and the maximum reduction was seen in $\mathrm{G}_{4}$ that is from $251.75 \mathrm{mg} / \mathrm{dL}$ to $195.75 \mathrm{mg} / \mathrm{dL}$ when this group was treated with combined mixture of turmeric and black cumin powder.

\section{Insulin}

Insulin is a hormone that plays crucial part in the regulation of blood sugar levels. During the period of 45 days insulin level was measured 4 times that was at the start of the study then after every 15 days throughout the trial.

Mean Table 2 for the insulin level of the rats showed that insulin level in the control group $\mathrm{G}_{0}$ was normal and $6.64 \mu \mathrm{U} / \mathrm{mL}$ at 0 day and remained in the normal range till the $45^{\text {th }}$ day. Then the insulin level was reduced in $\mathrm{G}_{1}, \mathrm{G}_{2}$, $\mathrm{G}_{3}$ and $\mathrm{G}_{4}$ due to Streptozotocin. The insulin level in $G_{1}$ remained lower till the end of study because no treatment has been given to this group and insulin level was improved in $\mathrm{G}_{2}, \mathrm{G}_{3}$ and $\mathrm{G}_{4}$ when these groups were treated with turmeric and black cumin and the maximum improvement was seen in turmeric treated group that was $\mathrm{G}_{2}$ from $5.805 \mu \mathrm{U} / \mathrm{mL}$ to $7.012 \mu \mathrm{U} / \mathrm{mL}$ because turmeric is responsible for significant production of insulin. 
Table 1. Mean \pm SD value of blood glucose level $(\mathrm{mg} / \mathrm{dL})$ of rats treated with turmeric and black cumin powder

\begin{tabular}{|c|c|c|c|c|c|}
\hline Groups & 0 Day & 15 Day & 30 Day & 45 Day & Means \\
\hline $\mathbf{G}_{\mathbf{0}}$ & $108.75 \pm 7.5$ & $111 \pm 4.08$ & $113.25 \pm 3.59$ & $113.75 \pm 5.05$ & $111.68 \pm 5.14^{\mathrm{c}}$ \\
\hline $\mathbf{G}_{1}$ & $252.25 \pm 1.25$ & $253.5 \pm 1.29$ & $254.25 \pm 1.5$ & $255 \pm 1.41$ & $253.75 \pm 1.612^{\mathrm{a}}$ \\
\hline $\mathbf{G}_{2}$ & $251.75 \pm 0.5$ & $217.5 \pm 6.49$ & $212.75 \pm 6.60$ & $208.5 \pm 5.97$ & $222.62 \pm 18.34^{\mathrm{b}}$ \\
\hline $\mathbf{G}_{3}$ & $251.5 \pm 0.57$ & $219.25 \pm 11.35$ & $189.5 \pm 57.07$ & $205.25 \pm 4.42$ & $216.37 \pm 35.18^{\mathrm{b}}$ \\
\hline $\mathbf{G}_{4}$ & $251.75 \pm 0.95$ & $213 \pm 2.44$ & $208.5 \pm 3.10$ & $195.75 \pm 1.70$ & $217.25 \pm 21.67^{\mathrm{b}}$ \\
\hline Means & $223.2 \pm 58.79^{\mathrm{a}}$ & $253 \pm 49.70^{\mathrm{b}}$ & $195.65 \pm 52.74^{\mathrm{b}}$ & $195.65 \pm 47.13^{\mathrm{b}}$ & \\
\hline
\end{tabular}

Means sharing similar letter in row or column are non-significant while means sharing different letter in row or column are significant

Table 2. Mean \pm SD value of insulin level $(\mu \mathrm{U} / \mathrm{mL})$ of rats treated with turmeric and black cumin powder

\begin{tabular}{|c|c|c|c|c|c|}
\hline Groups & 0 Day & 15 Day & 30 Day & 45 Day & Means \\
\hline $\mathbf{G}_{\mathbf{0}}$ & $6.647 \pm 0.294$ & $6.65 \pm 0.285$ & $6.657 \pm 0.286$ & $6.66 \pm 0.289$ & $6.653 \pm 0.258^{\mathrm{a}}$ \\
\hline $\mathbf{G}_{\mathbf{1}}$ & $5.022 \pm 0.244$ & $4.835 \pm 0.277$ & $4.697 \pm 0.278$ & $4.602 \pm 0.254$ & $4.789 \pm 0.287^{\mathrm{d}}$ \\
\hline $\mathbf{G}_{\mathbf{2}}$ & $5.805 \pm 0.465$ & $6.195 \pm 0.440$ & $6.66 \pm 0.528$ & $7.012 \pm 0.448$ & $6.418 \pm 0.633^{\mathrm{ab}}$ \\
\hline $\mathbf{G}_{\mathbf{3}}$ & $5.44 \pm 0.676$ & $5.817 \pm 0.551$ & $6.162 \pm 0.527$ & $6.622 \pm 0.659$ & $6.010 \pm 0.705^{\mathrm{bc}}$ \\
\hline $\mathbf{G}_{4}$ & $5.307 \pm 0.498$ & $5.865 \pm 0.586$ & $6.207 \pm 0.478$ & $6.47 \pm 0.458$ & $5.962 \pm 0.638^{\mathrm{c}}$ \\
\hline Means & $5.644 \pm 0.702^{\mathrm{c}}$ & $5.872 \pm 0.731^{\mathrm{bc}}$ & $6.077 \pm 0.835^{\mathrm{ab}}$ & $6.273 \pm 0.96^{\mathrm{a}}$ & \\
\hline
\end{tabular}

Means sharing similar letter in row or column are non-significant while means sharing different letter in row or column are significant

\section{Serum lipid profile}

Serum lipid was evaluated by analyzing the total cholesterol, high density lipoprotein, low density lipoprotein and triglycerides.

\section{Total cholesterol (TC)}

Cholesterol is a constituent (a steroid) that is necessary for life. It forms the membranes for cells in all structures and materials in the body. In this study when the blood glucose level was high then cholesterol level of the rats was also increased. Because hyperglycemia also disturbs the lipid profile and causes hyperlipidemia. The normal rat of $\mathrm{G}_{0}$ group has normal range of cholesterol and diabetic rats have high range of cholesterol. When these diabetic were treated with turmeric and black cumin their cholesterol level was improved. The (Fig. 1) showed that increase in $1.60 \%$ cholesterol level was observed in $\mathrm{G}_{1}$ which were diabetic rats and were not given any treatment. Their cholesterol level was remained high till the end of study. While $7.92 \%$ decrease in cholesterol level was seen in $\mathrm{G}_{2}, 10.10 \%$ decrease in $\mathrm{G}_{3}$ and $7.78 \%$ decrease in $\mathrm{G}_{4}$ diabetic rats that were given turmeric and black cumin powder and they showed improvement with this treatment throughout the study. Therefore, figure showed that turmeric and black cumin were effective in reducing cholesterol level due to their cholesterol lowering potential.

\section{Triglyceride (TG)}

Triglycerides (TG) are a type of fat (lipid) present in our blood. High triglyceride could be regulated by physical activity, weight control, by picking better fat. In this study the triglyceride level was also increased in diabetic rats due to streptozotocin. The normal non-diabetic rats of $\mathrm{G}_{0}$ was normal percentage of triglyceride and diabetic rats of group $\mathrm{G}_{1}, \mathrm{G}_{2}, \mathrm{G}_{3}$ and $\mathrm{G}_{4}$ showed high range of triglyceride. The (Fig. 2) showed that increase in $4.52 \%$ triglyceride was observed 
in $\mathrm{G}_{1}$ that were diabetic rats and were not received any treatment. Their triglyceride (TG) levels were remained high till the end of study. The triglyceride level of diabetic rats of $\mathrm{G}_{2}, \mathrm{G}_{3}$ and $\mathrm{G}_{4}$ were decreased because these groups were treated with turmeric and black cumin. The decrease of $6.92 \%$ was observed in $\mathrm{G}_{2}, 8.62 \%$ decrease in $\mathrm{G}_{3}$ and $6.31 \%$ decrease in triglyceride was seen in $\mathrm{G}_{4}$ because turmeric and black cumin have triglyceride lowering potential.

Low Density Lipoprotein Cholesterol (LDL-C)

Low density lipoprotein cholesterol generally stated as 'bad' cholesterol. Raised LDL levels are related with greater risk of heart disease. Hyperglycemia also cause increase in low density lipoprotein cholesterol in rats. The (Fig. 3) showed that normal non diabetic rats of $\mathrm{G}_{0}$ have normal percentage range while diabetic rats of $\mathrm{G}_{1}$ showed increase percentage of low density lipoprotein level. The Low density lipoprotein cholesterol (LDL-C) was increase to $15.92 \%$ in $\mathrm{G}_{1}$ that were diabetic rats and their LDL cholesterol was remained high till the end because this group has not received any treatment. The LDL cholesterol percentage was decrease in diabetic rats of group $\mathrm{G}_{2}, \mathrm{G}_{3}$ and $\mathrm{G}_{4}$ that were treated with turmeric and black cumin i.e., $16.96 \%$ decrease was observed in $\mathrm{G}_{2}, 19.29 \%$ decrease in $\mathrm{G}_{3}$ and $21.92 \%$ decrease was seen in $\mathrm{G}_{4}$ due to hypolipidemic potential of turmeric and black cumin.

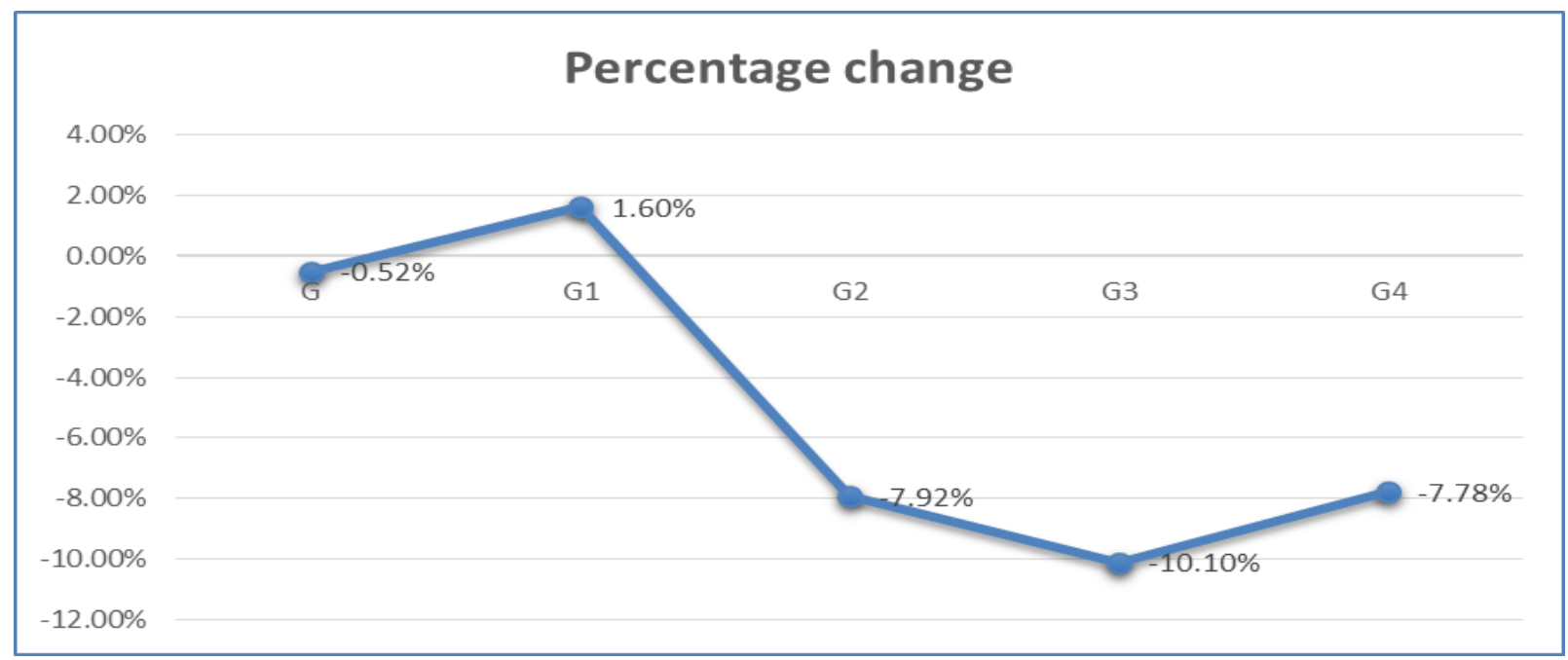

Figure 1. Comparison of percentage change of total cholesterol level (mg/dL) of rats

$\mathrm{G}_{0}($ normal $)=$ Normal diet

$\mathrm{G}_{1}($ diabetic control $)=$ Normal diet

+ Streptozotocin

$\mathrm{G}_{2}($ diabetic $)=$ Normal diet + Turmeric powder $2 \mathrm{~g}$

$\mathrm{G}_{3}($ diabetic $)=$ Normal diet + Black cumin powder $3 \mathrm{~g}$

$\mathrm{G}_{4}($ diabetic $)=$ Normal diet + Combination of both turmeric powder $1 \mathrm{~g}$ and black cumin powder $1.5 \mathrm{~g}$ 


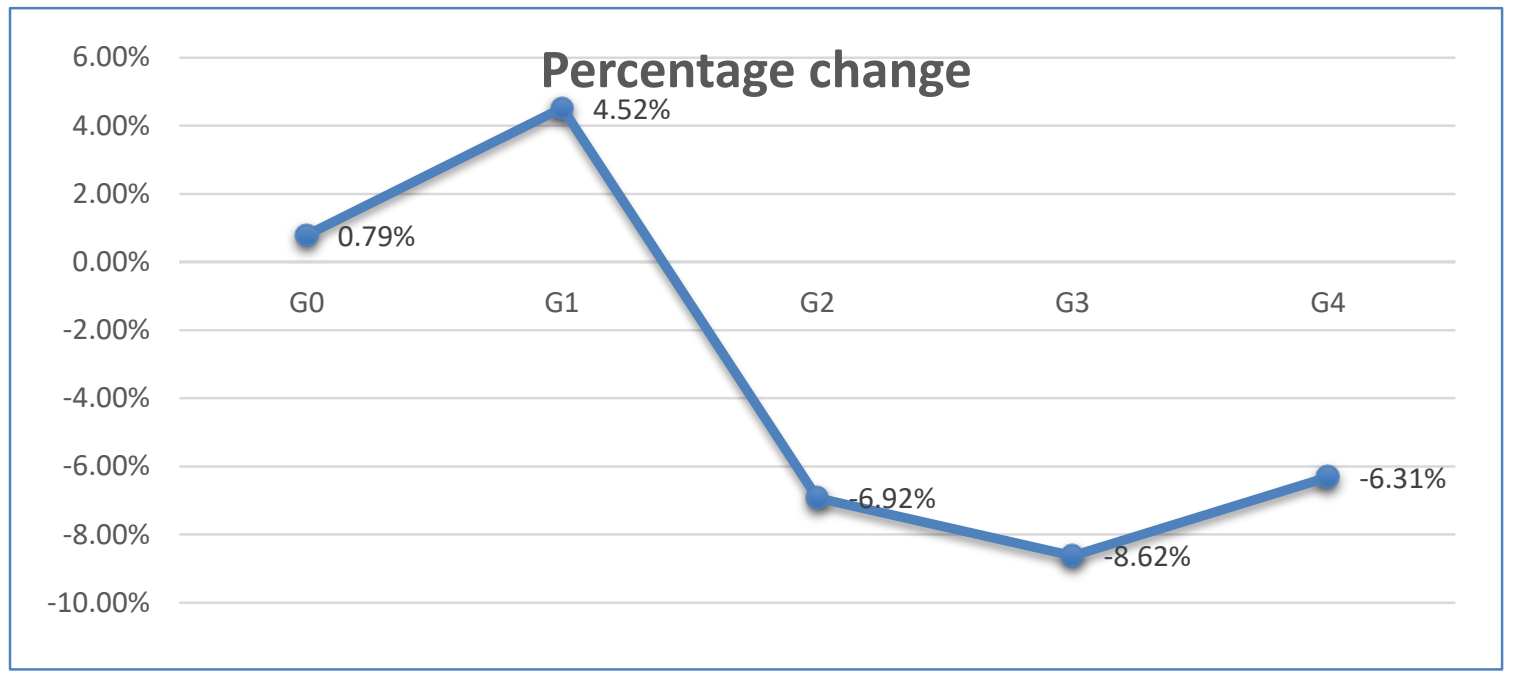

Figure 2. Comparison of percentage change in TG level (mg/dL) of rats

$\mathrm{G}_{0}($ normal $)=$ Normal diet

$\mathrm{G}_{1}($ diabetic control $)=$ Normal diet + Streptozotocin

$\mathrm{G}_{2}($ diabetic $)=$ Normal diet + Turmeric powder $2 \mathrm{~g}$

$\mathrm{G}_{3}($ diabetic $)=$ Normal diet + Black cumin powder $3 \mathrm{~g}$

$\mathrm{G}_{4}($ diabetic $)=$ Normal diet + Combination of both turmeric powder $1 \mathrm{~g}$ and black cumin powder $1.5 \mathrm{~g}$

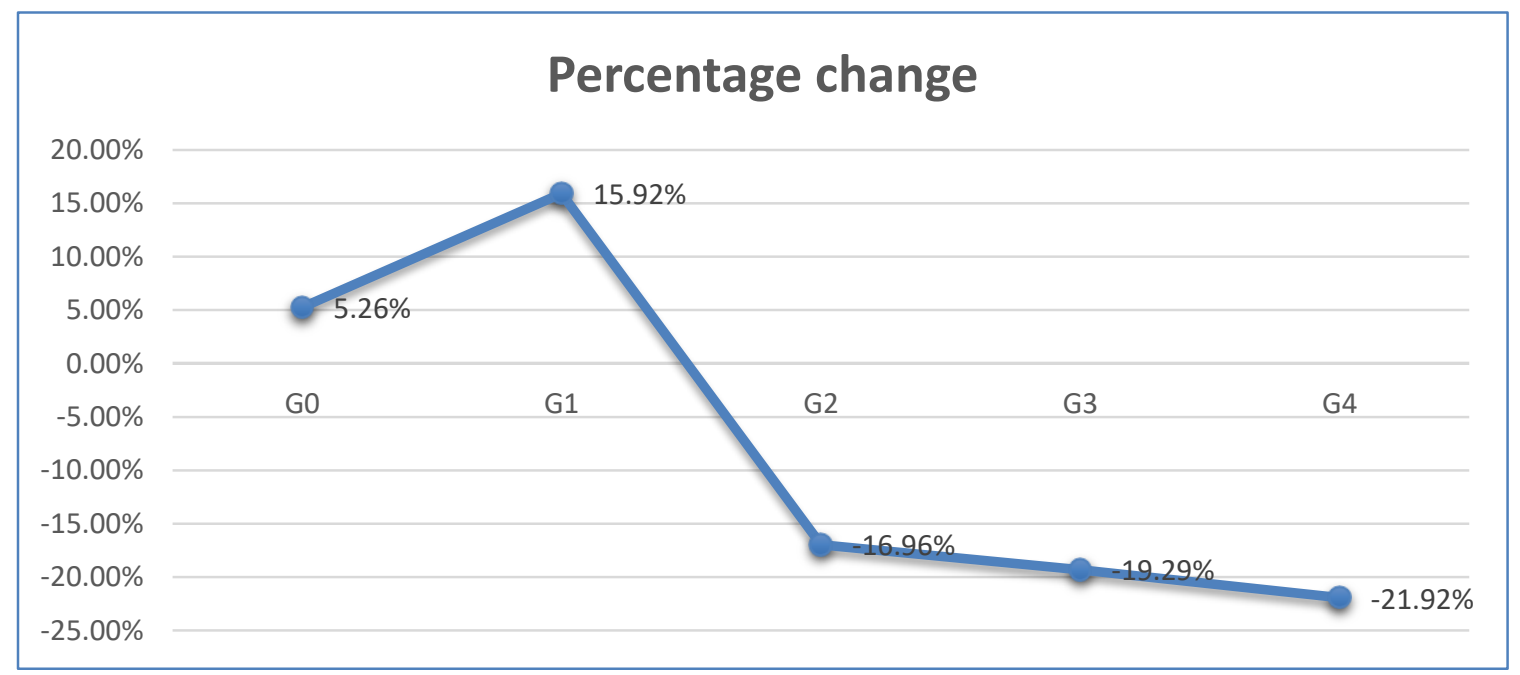

Figure 3. Comparison of percentage change in LDL-C level $(\mathrm{mg} / \mathrm{dL})$ of rats

$\mathrm{G}_{0}($ normal $)=$ Normal diet

$\mathrm{G}_{1}($ diabetic control $)=$ Normal diet + Streptozotocin

$\mathrm{G}_{2}$ (diabetic) $=$ Normal diet + Turmeric powder $2 \mathrm{~g}$

$\mathrm{G}_{3}$ (diabetic) $=$ Normal diet + Black cumin powder $3 \mathrm{~g}$

$\mathrm{G}_{4}($ diabetic $)=$ Normal diet + Combination of both turmeric powder $1 \mathrm{~g}$ and black cumin powder $1.5 \mathrm{~g}$

\section{High Density Lipoprotein cholesterol (HDL-C)}

High density lipoprotein cholesterol (HDLC) is frequently stated to as "good" cholesterol. High density cholesterol takes excess cholesterol in our blood and put it back to liver where it's broken down and detached from your body. It is associated with lesser risk of heart disease. When the rats were made diabetic by streptozotocin, it 
also disturbs their lipid profile which results in increased level of bad cholesterol and decreased level of good cholesterol which is high density lipoprotein. The (Fig. 4) showed that normal non diabetic rats of $\mathrm{G}_{0}$ have normal percentage of HDL cholesterol while the diabetic rats of group $\mathrm{G}_{1}$ revealed decrease in HDL cholesterol level. The $17.34 \%$ decrease in HDL cholesterol was observed in $\mathrm{G}_{1}$ and it remained low till the end of study because this group has not been treated with turmeric and black cumin powder. The HDL cholesterol level was improved in diabetic rats of group $\mathrm{G}_{2}, \mathrm{G}_{3}$ and $\mathrm{G}_{4}$ as these rats were given turmeric and black cumin i.e., $12.37 \%$ increase was seen in $\mathrm{G}_{2}, 27.55 \%$ increase in $\mathrm{G}_{3}$ and $9.09 \%$ increase was observe in $\mathrm{G}_{4}$ as these rats were given turmeric and black cumin in different doses. So the figure improved that turmeric and black cumin have potential to increase the level of good cholesterol.

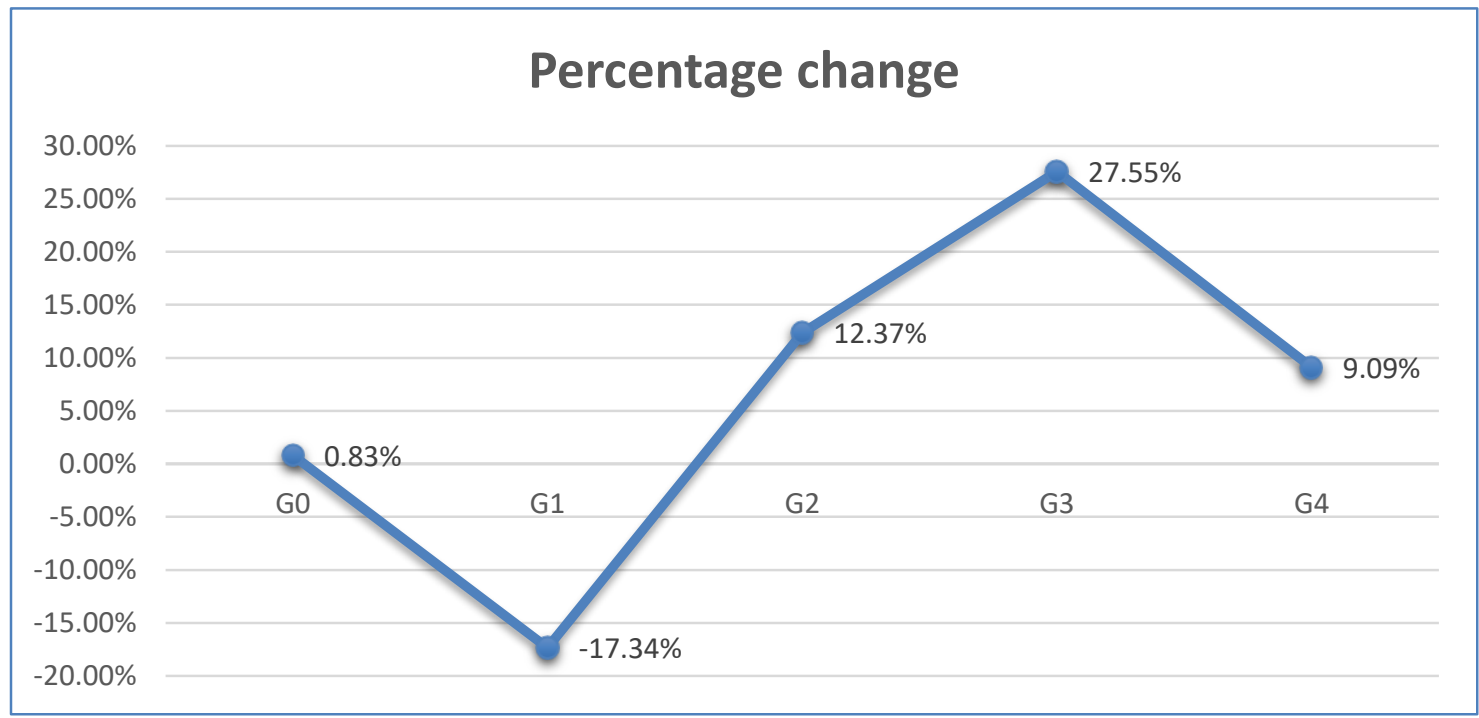

Figure 4. Comparison of percentage change in HDL-C (mg/dL) of rats

$\mathrm{G}_{0}($ normal $)=$ Normal diet

$\mathrm{G}_{1}($ diabetic control $)=$ Normal diet + Streptozotocin

$\mathrm{G}_{2}$ (diabetic) $=$ Normal diet + Turmeric powder $2 \mathrm{~g}$

$\mathrm{G}_{3}($ diabetic $)=$ Normal diet + Black cumin powder $3 \mathrm{~g}$

$\mathrm{G}_{4}($ diabetic $)=$ Normal diet + Combination of both turmeric powder $1 \mathrm{~g}$ and black cumin powder 1.5

\section{Discussion}

Functional foods have achieved importance for purpose of managing diet related disorders. Functional foods such as flavonoids and polyphenols rich food play a principle role in the management of diabetes mellitus, improvement of cholesterol level and also helpful in the maintenance of body weight. Diabetes mellitus requires lifestyle management and consumption of active nutrients that contain all functional compounds in them. Polyphenols are the phytochemicals that are being utilized to combat chronic diseases, reduce the severity and progression of human ailments and also helpful in the reduction of oxidative stress which is linked with diabetes mellitus [25]. Diabetes mellitus is the condition that disturbs the metabolic equilibrium of lipid and carbohydrate and insulin levels are inappropriately maintained. This will lead to rise in the blood glucose level. Hyperglycemia occurs when this irregular homeostasis fails to return to normal level and it will ultimately return to a metabolic disorder called diabetes mellitus [26]. 
Diabetes mellitus has numerous effects such as blindness, increased thirst, increased urination, renal failure and diabetic nephropathy, diabetic neuropathy and diabetic patients are also increased risk of developing heart diseases [27]. Diabetes is a hyperglycemic condition due to insulin action deficiency, but insulin also greatly affects serum lipids. Serum lipid disorders (dyslipidemia), regardless of insulin deficiency or insulin resistance, are usually seen in diabetic populations. It is no doubt that low-density lipoprotein (LDL)cholesterol (C) is the most important risk factor for systemic atherosclerotic disease (CVD), such as coronary artery disease. However, in diabetic populations, extreme hypercholesterolemia is not commonly found but rather hypertriglyceridemia and lowdensity lipoprotein (HDL-C) are more usual. Oxidative imbalance plays a major part in the progression of disease. Free radicals are made in unequal proportion in diabetes by oxidation of glucose, non-enzymatic glycation and ultimate oxidative degeneration of glycated protein. Unusually increased level of free radicals and concurrent reduction in defense system of antioxidant prompt danger to enzymes and cell organelles, expanded degradation of lipids and decreased ability of cells to respond to insulin effectively. Oxidation stress is responsible for progression of diabetes and diabetes related complication [28]. Treatment of diabetes mellitus requires modification of diet and management of lifestyle through diet related therapies. World health organization stated that treatment with medicinal plant herbs is beneficial in correcting diabetes and its related consequences. These plant herbs beside their antioxidant effects are also effective in reducing oxidative stress damage and thus proved beneficial for hyperglycemic conditions [29].
Turmeric is an anti-diabetic plant and has medicinal properties to fight against infections because of its antioxidant potential. Turmeric contain curcuminoids that also possess medicinal properties such as they act as anti-oxidant and have hypoglycemic and hypolipidemic potential and helps in the defense of $\beta$-cells from damaging effect of free radicals.. One study reported that administration of $300 \mathrm{mg} / \mathrm{kg}$ body weight of turmeric powder to rats for 12 weeks result in remarkable reduction in blood glucose level. Turmeric is responsible for the significant production of insulin, increased antioxidant mechanism and reduction in the oxidative degradation of lipid. The turmeric powder has potential to reduce elevated level of blood glucose as it is protective against oxidative stress and also provides protection from destruction of pancreatic $\beta$-cell and imposes specific impact on glucose and insulin production [15]. Diabetes induced many changes in lipid profile as hyperlipidemia and hypercholesterolemia observed in STZ diabetic rats. The hypocholesterolemic effect of turmeric reported to be due to up-regulation of cholesterol $7 \alpha$-hydroxylase in rats [22].

Another study reported that administration of $2 \mathrm{~g}$ turmeric supplementation for 4 weeks to rats that were on metformin therapy results in reduction of blood glucose level, HbA1c, reduction in lipid abnormalities, impose beneficial effect on reducing low density lipoprotein cholesterol, increasing high density lipoprotein cholesterol, increasing antioxidant mechanism and lessen the inflammatory markers. Thus turmeric is provided to be effective therapy in managing diabetes and related disorders [30].

Black cumin has scientific name Nigella sativa and is generally called as kalonji. Black cumin and its compounds are effective in the improvement of blood glucose level. Oxidative stress is important factor in generating diabetes mellitus as oxidative 
stress reduces effectiveness of $\beta$-cell of pancreas that cause issues in the production of insulin. Nigella sativa and its compounds are proved beneficial in reducing the oxidative stress and guard the pancreatic $\beta$ cells from mutilation. The hypoglycemic potential of Nigella sativa has been attributed because of the maintenance of integrity of $\beta$ cells with partial multiplication of $\beta$-cells results in elevated level of insulin. The hypoglycemic and hypolipidemic potential of Nigella sativa is because of the presence of antioxidant components that are thymoquinone and di-thymoquinone [31]. Black cumin helps in the enhancement of antioxidant system. Decreased level of oxidative imbalance is helpful for protecting $\beta$-cell, islets cells increased in number, diminished insulin becomes less and secretion of insulin becomes more. The Nigella sativa prevent tissue against lipid degradation and boost up the function of enzyme that is include in the metabolism of lipid [32].

In the present research therapeutic potential of turmeric and black cumin observed in the efficacy study on albino rats. Rats were distributed into 5 groups, Normal rats $G_{0}$ receiving only normal diet, diabetic rats $G_{1}$ receiving normal diet, diabetic rats $\mathrm{G}_{2}$ receiving normal diet $+2 \mathrm{~g}$ turmeric powder, diabetic rats $\mathrm{G}_{3}$ receiving normal diet $+3 \mathrm{~g}$ black cumin powder and diabetic rats $\mathrm{G}_{4}$ receiving normal diet and combined mixture of $1 \mathrm{~g}$ turmeric powder $+1.5 \mathrm{~g}$ black cumin powder.

Blood glucose concentration was greatly improved by combined mixture of turmeric and black cumin i.e., from $251.75 \mathrm{mg} / \mathrm{dL}$ to $195.75 \mathrm{mg} / \mathrm{dL}$ in the present study. The insulin level was also improved by the turmeric and black cumin but more improvement was seen in turmeric treated group which is from $5.805 \mu \mathrm{U} / \mathrm{mL}$ to 7.012 $\mu \mathrm{U} / \mathrm{mL}$. In addition to manage the diabetes mellitus, turmeric and black cumin also have hypolipidemic potential i.e., they are effective in the management of serum lipid profile.

In this study percentage comparison of lipid profile of rats showed that turmeric and black cumin improves the total cholesterol as percentage of total cholesterol was decrease in turmeric and black cumin treated group, Triglyceride level percentage also decrease in turmeric and black cumin treated group as compared to non-treated diabetic rats, LDL bad cholesterol percentage also decreased by turmeric and black cumin treatment while HDL good cholesterol percentage increased in turmeric and black cumin treated group as compared to non-treated diabetic rats.

The hypolipedemic potential of NS is due to occurrence of numerous components such as flavonoids, sterols, fiber and polyunsaturated fatty acids. Nigella sativa seeds have potential for inhibition of cholesterol absorption and enhancement in the synthesis of bile acid. The active compound of nigella sativa thymoquinone prevent non enzymatic oxidation of lipids and control the synthesis of cholesterol through the modulate HMGCoA reductase enzyme that regulate cholesterol synthesis and low density lipoprotein receptor gene [33]. One study reported that black cumin powder also has potential to normalize lipid profile such that $1 \mathrm{~g}$ administration of black cumin powder for 2 months in patients with elevated level of cholesterol results in reduction of low density lipoprotein, total cholesterol and also decrease triglyceride level as well significant enhancement in the high density lipoprotein [34]. This lipid lowering power of black cumin is ascribed due the presence of active compound thymoquinone and numerous other compounds such as flavonoids, and sterol [35].

The management of metabolic syndrome requires lifestyle management through natural plant based products that are used for medicinal purposes and numerous 
medications that made from natural herbs that are favorable in the cure of ailments like diabetes mellitus.

\section{Conclusion}

The study revealed that turmeric and black cumin have potential to lower blood glucose level and bad cholesterol and increase good cholesterol due to presence of numerous antioxidants and polyphenols. Diabetes mellitus is also a risk factor for other diseases like cardiovascular disease and result of study showed that it can be cured through dietary modification. Therefore, turmeric and black cumin are effective in controlling diabetes mellitus and related disorder.

\section{Authors' contributions}

Conceived and designed the experiments: $S$ Mobeen, MS Butt \& MK Sharif, Performed the experiments: S Mobeen, Analyzed the data: S Mobeen \& M Rizwan, Contributed reagents/ materials/ analysis tools: $\mathrm{S}$ Mobeen \& S Amin, Wrote the paper: S Mobeen.

\section{References}

1. Jamshidi-Kia F, Lorigooini Z \& AminiKhoei H (2018). Medicinal plants: past history and future perspectives. $J$ Herbmed Pharmacol 7(1): 1-7.

2. Irshad S, Muazzam A, Shahid Z \& Dalyrmple, MB (2018). Curcuma longa (turmeric): An auspicious spice for antibacterial, phytochemical and antioxidant activities. Pak J Pharm Sci 31(6): 2689-2696.

3. Najafian M (2015). The effects of curcumin on alpha amylase in diabetic rats. Zahedan J Res Med Sci 17(12): 1-7.

4. Ghorbani Z, Hekmatdoost A \& Mirmiran P (2014). Antihyperglycemic and insulin sensitizer effect of turmeric and its principle constituent curcumin. Int $J$ Endocrinol Metab 12(4): 1-9.

5. Mannan AA \& Kahvic M (2010). Ibn Sina: A tribute. Gulf J Oncolog 1(7):60-63.

6. Kaskoos RA (2011). Fatty acid composition of black cumin oil from Iraq. Res J Med Plant 5(1): 85-89.

7. Hussain DA \& Hussain MM (2016). Nigella sativa (black seed) is an effective herbal remedy for every disease except death - a Prophetic statement which modern scientists confirm unanimously: A review. Adv Med Plant Res 4(2): 27-57.

8. Ain Q \& Sadeeqa S (2018). Diabetes mellitus: A case study. Virol Immunol J 2(5): 1-3.

9. Santoshkumar J, Mariguddi DD \& Manjunath S (2016). Comparative study of hypolidemic effects of ethanolic extract of rhizomes of Curcuma longa (turmeric) versus pioglitazone in alloxan induced diabetic rats. Int J Pharmacol Clin Sci 5(1): 5-11.

10. Lipinski B (2001). Pathophysiology of oxidative stress in diabetes mellitus. $J$ Diabetes Complications 15(4): 203-210.

11. Pham-Huy LA, He H \& Pham-Huy C (2008). Free radicals, antioxidants in diseases and health. Int J Biomed Sci 4(2): 89-96.

12. Mahfouz MKM (2010). Curcumin / irbesartan combination Improves insulin sensitivity and ameliorates serum proinflammatory cytokines levels in diabetes rat model. Am J Sci 6(11): 1051-1059.

13. Kuroda M, Mimaki Y, Nishiyama T, Mae T, Kishida H, Tsukagawa M, Takahashi K, Kawada T, Nakagawa K \& Kitahara M (2005). Hypoglycemic effects of turmeric (Curcuma longa L. rhizomes) on genetically diabetic KK-Ay mice. Biol Pharm Bull 28(5): 937-939.

14. Suryanarayana P, Saraswat M, Mrudula T, Krishna TP, Krishnaswamy K \& Reddy GB (2005). Curcumin and turmeric delay streptozocin- induced diabetic cataract in rats. Investig Ophthalmol Vis Sci 46(6): 2092-2099.

15. Latif J, Mukhtar S \& Qamar I (2017). Hypoglycemic effect of turmeric in alloxan induced diabetic rat. Ann. King Edw Med Univ 23(3): 290-294.

16. Rivera-Espinoza Y \& Muriel P (2009). Pharmacological actions of curcumin in liver diseases or damage. Liver Int 29(10): 1457-1466.

17. Li S, Yuan W, Deng G, Wang P, Yang P \& Aggarwal BB (2011). Chemical 
composition and product quality control of turmeric (Curcuma longa L.). Pharm Crop 2(1): $28-54$

18. Rivera-Mancia S, Trujillo J \& Chaverri JP (2018). Utility of curcumin for the treatment of diabetes mellitus: evidence from preclinical and clinical studies. $J$ Nutr Intermed Metab 14: 29-41.

19. Zhang DW, Fu M, Gao SH \& Liu JL (2013). Curcumin and diabetes: a systemic review. Evid Based Complement Alternat Med 54(1): 1-16.

20. Shafiq H, Ahmad A, Masud T \& Kaleem M (2014). Cardioproective and anticancer therapeutic potential of Nigella Sativa. Iran J Basic Med Sci 17(12): 967-979.

21. Stadler K (2012). Oxidative stress in diabetes. Adv Exp Med Biol 771(1): 272287.

22. El-Bahr SM, Taha NM, Korshom MA, Mandour AEWA \& Lebda MA (2014). Influence of combined administration of turmeric and black seed on selected biochemical parameter of diabetic rats. Alex J Vet Sci 41(1): 19-27.

23. Al-Nawazi MH \& El-Bahr SM (2012). Hypolipidemic and hypocholestrolemic effect of medicinal plant combination in the diet of rats: Black Cumin Seed (Nigella Sativa) and Turmeric (Curcumin). J Anim Vet Adv 11(12): 1-8.

24. Montogomery, D.C. 2008. Design and Analysis of Experiments. $7^{\text {th }}$ Ed. John Wiley and Sons. Inc. Hoboken, NJ, USA.

25. Xiao JB \& Hogger P (2015). Dietary polyphenols and type 2 diabetes: current insights and future perspectives. Curr Med Chem 21(1): 23-38.

26. Tiwari AK \& Rao JM (2002). Diabetes mellitus and multiple therapeutics approaches of phytochemicals: present status and future prospects. Curr Sci 83(1): 30-38.

27. Varughese GI, Scarpello JH (2006). Treating dyslipidaemia in the setting of diabetes mellitus and cardiovascular disease: a less commonly perceived therapeutic perspective in clinical practice. Int J Clin Pract 60(7): 884-888.

28. Gupta SC, Sung B, Kim JH, Prasad S, Li S \& Aggarwal BB (2013). Multitargeting by turmeric, the golden spice: From kitchen to clinic. Mol Nutr Food Res 57(9): 15101528.

29. Nazarian-Samani Z, Sewell R, Loorigoini Z \& Rafieian-Kopaei M (2018). Medicinal plants with multiple effect on diabetes mellitus and its complications. Curr Diab Rep 18(10): 1-13.

30. Selvi NMK, Sridhar MG, Swaminathan RP \& Sripradha R (2015). Efficacy of Turmeric as Adjuvant Therapy in Type 2 Diabetic Patients. Ind $J$ clinic biochem 30(2): 180-186.

31. Fararh KM, Ibrahim AK \& Elsonosy YA (2010). Thymoquinone enhance the activities of enzyme related to energy metabolism in peripheral leukocytes of diabetic rat. Res Vet Sci 88(3): 400-405.

32. Abdelmeguid NE, Fakhoury R, Kamal SM \& Al Wafai RJ (2010). Effects of Nigella sativa and thymoquinone on biochemical and subcellular changes in pancreatic bcells of streptozotocin-induced diabetic rats. J Diabetes 2(4): 256-266.

33. Abbas AH (2018). Anti-hyperglycemic, Anti-hyperlipidemic effects of ethanol extract of Nigella Sativa seeds in high fat diet induced hyperglycemic mice. World $J$ Pharm Pharm Sci 7(1): 110-122.

34. Bhatti IU, Rehman FU, Khan MA, Marwat SK (2009). Effect of prophetic medicine kalonji Nigella sativa on lipid profile of human beings. As in vivo approach. World App Sci J 6(8): 1053-1057.

35. Shabana A, El-Menyar A, Asim M, Azzeh H \& Al-Thani H (2013). Cardiovascular benefits of black cumin (Nigella sativa). Cardiovasc Toxicol 13(1): 9-12. 